\title{
Pollutant Spreading in a Small Stream: A Case Study in Mala Nitra Canal in Slovakia
}

\author{
Yvetta Velísková • Marek Sokáč • Peter Halaj • \\ Márta Koczka Bara • Renáta Dulovičová • \\ Radoslav Schügerl
}

Received: 15 November 2013 / Accepted: 7 January 2014/Published online: 6 May 2014

(C) Springer International Publishing Switzerland 2014

\begin{abstract}
The Water Framework Directive requires as an obligatory goal to achieve and to keep "good water quality" status within the defined period (for Slovakia - up to the year 2015). For surface waters, the main criterion is the ecological and chemical status of the water. Mathematical and numerical modelling allows evaluating various situations of contaminants spreading in rivers (from everyday wastewater disposal through fatal accidents and discharges of the toxic substances) without immediate destructive impact to the environment. Determination of longitudinal and transverse dispersion coefficient values, as the main hydrodynamic characteristics of the dispersion, has the highest extent of uncertainty for hydrodynamic models simulating pollutant transport in streams. This paper deals with the determination of dispersion coefficients based on field tracer experiments performed in a small modified stream (basic hydrodynamic parameters during the experiments were: discharge $Q=0.138$ $0.553 \mathrm{~m}^{3} \cdot \mathrm{s}^{-1}$, depth $h=0.29-0.48 \mathrm{~m}$, width $B=5.2-5.9 \mathrm{~m}$ ). During the experiments, various conditions and situations were taken into account, e.g., continuous and instantaneous pollution source, as well as various positions of pollution source along the river width, among others. Field measurements were evaluated using three different methods for dispersion coefficient determination: based on statistical evaluation, based on analytical solutions of advection-dispersion equation, and using numerical models. The dimensionless dispersion coefficients values were determined, which can be used for numerical simulation of pollutant transport in similar types of streams.
\end{abstract}

Keywords Dispersion coefficient · Field tracer experiments $\cdot$ Dimensionless dispersion coefficient $\cdot$ Numerical simulation $\cdot$ Pollutant spreading

Y. Velísková $(\bowtie) \cdot$ M. Koczka Bara $\cdot$ R. Dulovičová $\cdot$ R. Schügerl Institute of Hydrology, Slovak Academy of Sciences, Bratislava, Slovakia e-mail: yvetta.veliskova@savba.sk

M. Sokáč

Department of Sanitary and Environmental Engineering, Slovak University of Technology, Bratislava, Slovakia

P. Halaj

Department of Landscape Engineering, Slovak Agricultural University, Nitra, Slovakia 


\section{Introduction}

The development of the computer technologies enables to solve the ecological problems in water management practice very efficiently and without immediate destructive impact on the environment. Several mathematical and numerical models have been developed to simulate water quality in watersheds and pollutant spreading in streams, e.g.: WQMCAL (Jolánkai 2000), AGNSP (USDA), CORMIX (Jirka et al. 1996), QUAL2E (Brown and Barnwell 1987), SWMM (Rossman 2007), MIKE (DHI), ZNEC (Říha et al. 2000), MODI (Velísková 1995), OTIS (Runkel 1998), SIRENIE (Pekárová and Velísková 1998), and others. These models are able to simulate the real events of pollutant spreading in streams, however, the range of the reliability and accuracy of the results is very wide (Abbott 1978; Jolánkai 1992; Pekárová and Velísková 1998; Ř́ha et al. 2000; Rankinen et al. 2002; McInstyre et al. 2005). Simulation models are able to describe the transport of the contaminants even three-dimensionally, but, in this case, the model input requires a large amount of data and the development of the model structure is time-consuming. Two-dimensional modelling of the transport processes is fairly accurate, if applied to shallow waters without strong thermal stratification. Eventually, it can be used in detailed studies of pollutant movement into surface water, before a total mixing of transported substance across the section of flow occurs. After this moment, it is sufficient to apply a one-dimensional model of pollutant transport processes.

The models simulating pollutant transport in open channels require the determination of the dispersion coefficients among other input data. These coefficients could be exactly obtained by field measurements, directly reflecting conditions in an open channel. It is not always possible to obtain these coefficients in the field, because of financial or time reasons. Several authors (Bansal 1971; Elder 1959; Fischer et al. 1979; Jolánkai 1992; Krenkel and Orlob 1962; Kosorin 1995; Ř́ha et al. 2000; Swamee et al. 2000; Karcher et al. 2004) tried to derive empirical relations, especially for the longitudinal dispersion coefficient. Their studies could be used to estimate an approximate value of the dispersion coefficient.

The objective of this paper is the determination of dispersion coefficients from field measurements. Datasets from these measurements can be used in numerical simulation of various scenarios of pollutant spreading in the studied stream. The obtained coefficients can be used for another stream with similar flow conditions, as well.

\section{Theoretical Basis}

Dispersion, from the hydrodynamic point of view, is the spreading of mass from highly concentrated areas to less concentrated areas in a flowing fluid. Mass in flowing water is not transported only in the reach of streamline, but it is also gradually spreading to outside (laterally and vertically) in consequence of velocity pulsations and mass concentration differences. Mass dispersion with advection is the basic motion mechanism of particles transported in water.

There are several different ways of solving problems of pollutant spreading in open channels from the hydrological and hydraulics point of view, which can be divided into two main groups: 1) based on time series analysis; 2) based on hydrodynamic equations. The time series analysis is, in fact, an empirical approach, which does not consider the internal mechanism of mixing in the streams. It is simpler than the hydrodynamic approach but, on the other hand, its application is valid only for one particular river cross section, and for a narrow range of conditions for which it was derived. 
On the contrary, the hydrodynamic approach endeavours to understand and quantify mixing processes in a stream. It is substantially more universal, but hard to get input data is its limitation. The hydrodynamic models are based on advection-diffusion equation (ADE) and the majority of them are one-dimensional. Their disadvantage is inability to simulate the pollution spreading until the mixing of pollutants across the stream section is complete. The required time for this, especially in wide rivers, can be very long (Yotsukura and Sayre 1976; Sanders and Ward 1978; Fischer et al. 1979; Říha et al. 2000). Two-dimensional mixing models do not suffer from these limitations. The ADE for this case is:

$$
\frac{\partial(h c)}{\partial t}+\frac{\partial(h u c)}{\partial x}+\frac{\partial(h v c)}{\partial y}=\frac{\partial}{\partial x}\left(h D_{L} \frac{\partial c}{\partial x}\right)+\frac{\partial}{\partial y}\left(h D_{T} \frac{\partial c}{\partial y}\right)+\Delta C_{n c}+\Delta C_{l s}+\Delta C_{d z}
$$

where: $c$ is the mass concentration $\left[\mathrm{kg} \cdot \mathrm{m}^{-3}\right], D_{L}$ is the longitudinal dispersion coefficient $\left[\mathrm{m}^{2} \cdot \mathrm{s}^{-1}\right], D_{T}$ is the transverse dispersion coefficient $\left[\mathrm{m}^{2} \cdot \mathrm{s}^{-1}\right], h$ is the depth $[\mathrm{m}], t$ is the time $[\mathrm{s}]$, $x, y$ are the longitudinal and transverse coordinates $[\mathrm{m}], u, v$ are the depth-averaged longitudinal and transverse velocities [m.s $\left.{ }^{-1}\right], \Delta \mathrm{C}_{\mathrm{nc}}$ is the influence of non-conservation, $\Delta \mathrm{C}_{\mathrm{ls}}$ is the influence of local source of contaminant, and $\Delta \mathrm{C}_{\mathrm{dz}}$ is the influence of "dead zones".

The main parameters characterising the dispersion phenomenon are the dispersion coefficients in the relevant directions. Determination of these dispersion characteristics is the key task for solving problems of pollutant transport in streams and for modelling water quality.

As it follows from the international literature (Bansal 1971; Elder 1959; Fischer et al. 1979; Jolánkai 1992; Krenkel and Orlob 1962; Parker 1961; Ríha et al. 2000; Swamee et al. 2000; Karcher et al. 2004), as well as from local studies (Kosorin 1995; Pekárová and Velísková 1998), the derivation of the dispersion coefficient $D$ is achieved by several ways: from the researcher's own experience or from the various references, up to the application of special calculations. As the dispersion coefficient value is determined by turbulence intensity in the given stream section, its magnitude depends upon its main hydraulic characteristics.

Most of all published relations for dispersion coefficient determination are based on experimental results from laboratory physical models or directly from field measurements on the rivers. Their values are often published in the form of the so-called dimensionless dispersion coefficient (Fischer et al. 1979):

$$
p=\frac{D}{h \cdot u_{*}}
$$

where $p$ is the empirical dimensionless coefficient, $u_{*}$ is the shear velocity $\left[\mathrm{m} \cdot \mathrm{s}^{-1}\right], D$ is the longitudinal or transverse dispersion coefficient $\left[\mathrm{m}^{2} \cdot \mathrm{s}^{-1}\right]$, and $h$ is the water depth $[\mathrm{m}]$. This form is more suitable for applications in various flow conditions.

\section{Field Measurements}

\subsection{Description of Locality}

Field measurements were performed at an approximately $400 \mathrm{~m}$ long reach of the man-made channel of the Mala Nitra stream (Figs. 1 and 2). This stream is situated at the southwest part of Slovakia; measurements were performed in the region of Velky Kyr village $\left(\mathrm{N}+48^{\circ} 10^{\prime}\right.$ 50.02", E+189'19.60") (Fig. 3).

The Mala Nitra stream is a small, modified stream with a basin area of $76.6 \mathrm{~km}^{2}$. The regime of the stream discharges is affected by flow regulation through a weir located $15 \mathrm{~km}$ 

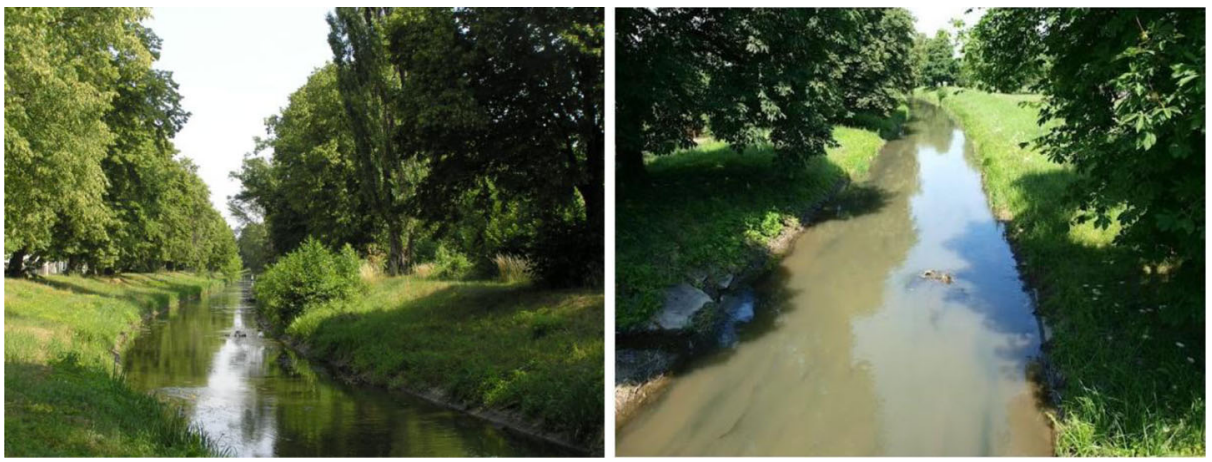

Fig. 1 Views of the Mala Nitra canal

upstream in the bifurcation point with the Nitra River. Cross sections had originally a trapezoidal shape with bottom width $b=4 \mathrm{~m}$, height $2.5 \mathrm{~m}$ and bank slope 1:2 (Fig. 2), but the discharge area along the stream has been slightly changed by natural morphological processes during the years. However, the selected study reach of the stream was picked out as a prismatic channel. There is a relatively long straight part with not so deep water depths (max. $0.65 \mathrm{~m}$ ), suitable for measurements without using a boat. The longitudinal bed slope is $1.5 \%$. The discharge values during the field experiments were measured with the Acoustic Doppler Velocimeter - FlowTracker 3D and were within the interval $0.138-0.553 \mathrm{~m}^{3} . \mathrm{s}^{-1}$. The roughness coefficient (for model HEC-RAS application) was determined based on field measurements (Limerinos 1970) and was $n=0.035$.

\subsection{Description of Field Measurement Method}

To determine the longitudinal dispersion coefficient, the tracer with a known quantity and concentration or conductivity was dosed into the geometric centre of the stream width at the beginning of the measured reach instantaneously. As tracer, salt $(\mathrm{NaCl})$ solution was used, which causes a conductivity change of flowing water. A single dose of tracer was 50-70 1, representing approximately $10-15 \%$ of the actual discharge in the stream. The tracer conductivity was $51.7-63 \mathrm{mS} / \mathrm{cm}$.

Subsequently, the time courses of conductivity changes were monitored in each measured cross section of the stream. Measured cross sections were at 100, 150, 175, 200, 225, 250, 275 and $300 \mathrm{~m}$ distance from the tracer injection point. Conductivity measurements were accomplished with portable conductivity meters, located at the centre of the measured cross section width. The vertical position (depth) of the probe was approximately $0.2 \mathrm{~m}$ below the water level, which represents depths from half up to one third of the water depth, depending on the

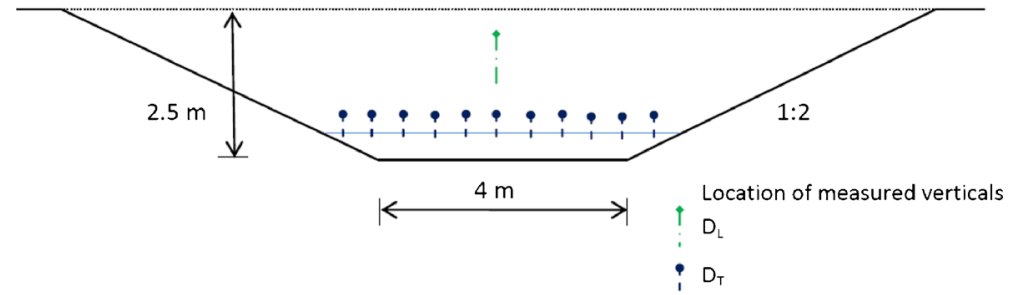

Fig. 2 Schematic of a prototype cross section with location of measured verticals 

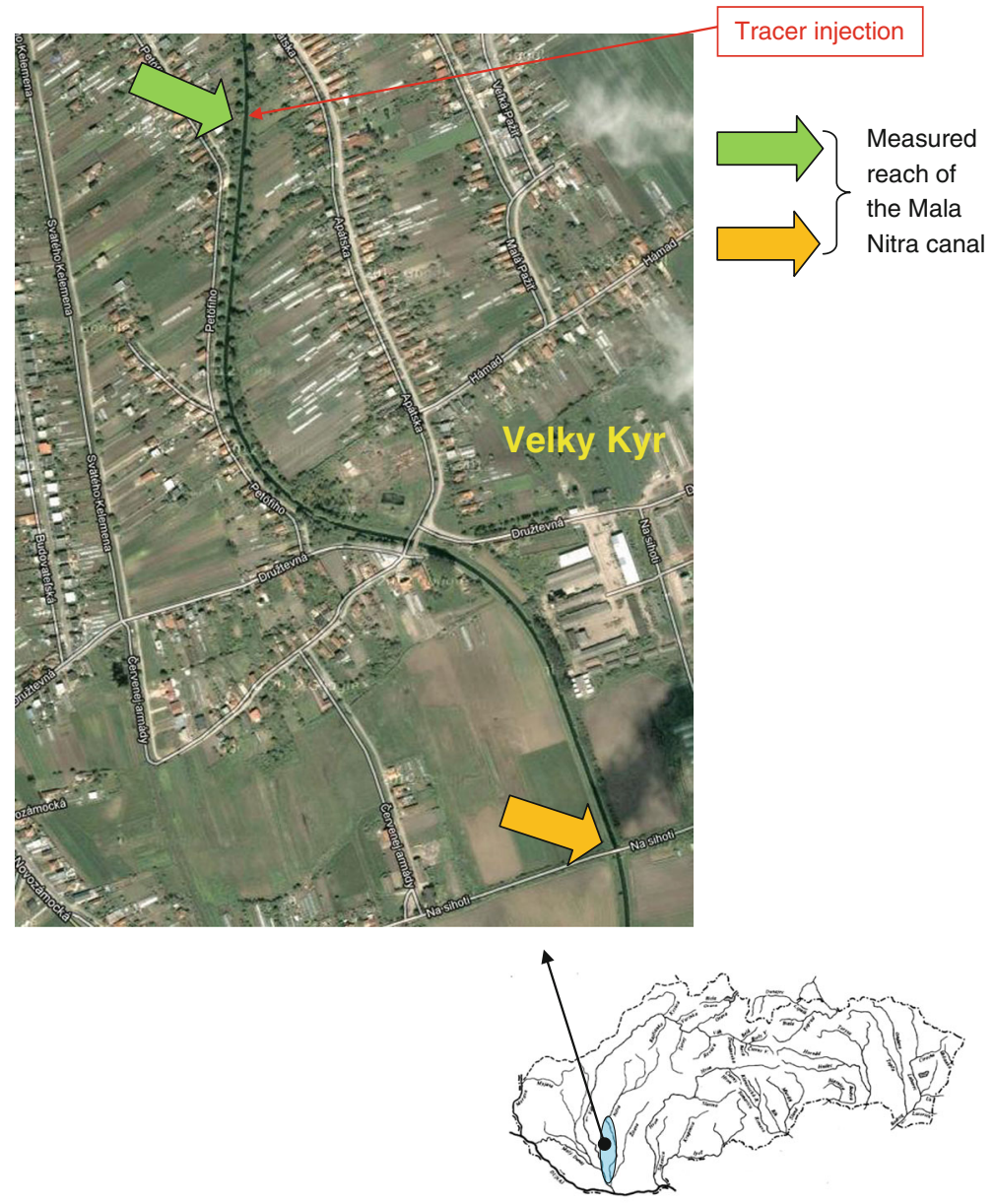

Fig. 3 Map of measured canal reach (https://maps.google.com/)

water depth in each measuring profile. Measurements were always carried out when conductivity values started rising (front of tracer wave) until achieving the original (background) conductivity values in each cross section. Each tracer experiment was repeated at least three times.

To determine the coefficient of transverse dispersion, a slightly different approach was used: the tracer was not dosed at once, i.e., instantaneously, but continuously (using a pump) with a known discharge and concentration or conductivity of the tracer. Tracer discharge $(\mathrm{NaCl}$ solution) was about $0.31 . \mathrm{s}^{-1}$. The tracer injection point was placed again at the initial cross section of the measured reach, but in some experiments it was placed at the centre of the cross section width, and in other cases at the surface water levels near the right or left bank of the same cross section of the measured reach. The vertical position of the probe was similar as during the measurements of the longitudinal dispersion coefficient; in the case of smaller depths the probe was placed in the centre of the vertical.

Conductivity values of surface water were recorded at every $0.5 \mathrm{~m}$ of each measured cross section (see Fig. 2). The distances of measured cross sections from 
the tracer injection were 30,97 and $150 \mathrm{~m}$. Measurements were repeated at least three times in each cross section.

The velocity distribution and discharge were measured in each cross section for all tracer experiments.

\subsection{Methods for Dispersion Coefficients Determination}

Field measurements were evaluated using three different methods for dispersion coefficients determination: based on analytical solutions of ADE, based on statistical evaluation and by use of numerical models.

The determination of longitudinal dispersion coefficient $\mathrm{D}_{\mathrm{L}}$ using the 1-D analytical solution of $\mathrm{ADE}$ was based on the following equation applicable for instantaneous injection of tracer (Cunge et al. 1985):

$$
c(x, t)=\frac{G}{2 A \sqrt{\pi D_{L} t}} \cdot \exp \left[-\frac{\left(x-u_{p} t\right)^{2}}{4 D_{L} t}\right]
$$

where $A$ is the flow area in a stream cross section $\left[\mathrm{m}^{2}\right], G$ is the mass of a tracer $[\mathrm{kg}], u_{p}$ is the mean cross-sectional velocity $\left(\mathrm{m} . \mathrm{s}^{-1}\right), D_{L}$ is the longitudinal dispersion coefficient $\left[\mathrm{m}^{2} . \mathrm{s}^{-1}\right], t$ is the time [s], $x$ is the distance from the tracer source [m].

All values in Eq. (3) were known from our field measurements (i.e., the distance $x$, the time $t$, the mean cross-sectional velocity $u_{p}$, the tracer mass $G$, the flow area $A$ ), except of the value of longitudinal dispersion coefficient $D_{L}$. The best estimation of $D_{L}$ arises from the best fit between measured and modelled values (provided by Eq. 3). For the determination of the best fit between measured and modelled values, the method of least squares was used. In other words, the sum of squared residuals (differences between measured and modelled values) for various values of $D_{L}$ was evaluated. The minimal value of the squared residuals sum determines the best estimation of the longitudinal dispersion coefficient value $D_{L}$. This procedure was performed for all measured cross sections and each experiment (see Fig. 4).

\section{Experiment Nr.DL1}

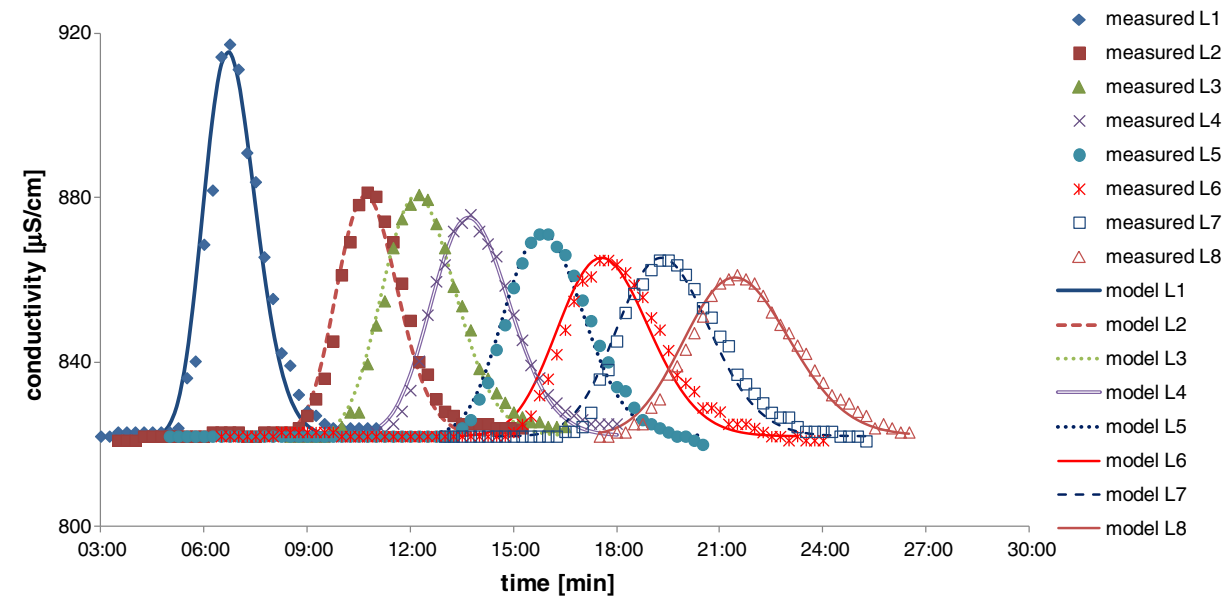

Fig. 4 Comparison of measured values from field experiments and results from the analytical solution of the advection-dispersion equation (Eq. 3)-L1 (100 m), L2 (150 m). L3 (175 m), L4 (200 m), L5 (225 m), L6 $(250 \mathrm{~m}), \mathrm{L} 7(275 \mathrm{~m}), 18(300 \mathrm{~m}) ; G=2 \mathrm{~kg}, \mathrm{u}_{\mathrm{p}}=(0.19-0.21) \mathrm{m} . \mathrm{s}^{-1}, A=(2.14-2.4) \mathrm{m}^{2}$ 
The second way for evaluation of the longitudinal dispersion coefficient is based on direct determination of the statistical parameters (standard deviation $\sigma$ and time $t$ ) of the acquired conductivity time courses. The principle of this method is to find the time which corresponds to the 15.87 and 84.13 percentile of the cumulative tracer mass curve. The distance of these two points is equal to $2 \sigma$ and the dispersion coefficient can be determined as (Socolofsky and Jirka 2005):

$$
D_{L}=\frac{\sigma^{2}}{2 t}=\frac{u_{p}^{2} \sigma_{t}^{2}}{2 t_{a}}
$$

where $\sigma$ is the standard deviation [m], $t$ is the time $[\mathrm{s}], u_{p}$ is a mean cross-sectional velocity $\left[\mathrm{m} . \mathrm{s}^{-1}\right], t_{a}$ is the average time $[\mathrm{s}]$, determined as average value of the time values, corresponding to the above mentioned tracer mass percentiles, and $\sigma_{t}$ is the standard deviation in time units [s], determined as a half of the time distance value between times, corresponding to the cumulative mass percentiles. To change the time dimension of measured standard deviation to the necessary spatial dimension we use $\sigma=u_{p} \cdot \sigma_{t .}$ (Socolofsky and Jirka 2005).

The third method is using a numerical model. For the determination of the longitudinal dispersion coefficient the model HEC-RAS was used. This model was developed by the United States Army Corps of Engineers (USACE) and it is designed to modelling complex phenomena and processes occurring in surface waters of river systems. This software allows the calculation of one-dimensional steady non-uniform and unsteady flow, solving of hydraulic engineering tasks, design of stream modifications, design of water works, pollution transport modelling, modelling of temperature of surface water, bed load transport, modelling of degradationaggradation processes in stream channels, etc. An advection-dispersion module is included with the used version of HEC-RAS. This new module uses the Quickest-Ultimate explicit numerical scheme to solve the one-dimensional ADE using a control volume approach.

This model was used for simulations of tracer experiments with various values of the longitudinal dispersion coefficient. Results of simulations were compared with measured conductivity distributions obtained during the field measurements. The minimal difference between measured and modelled values determines the value of the longitudinal dispersion coefficient for each one of the experiments. The result of one numerical experiment can be seen on Fig. 5.

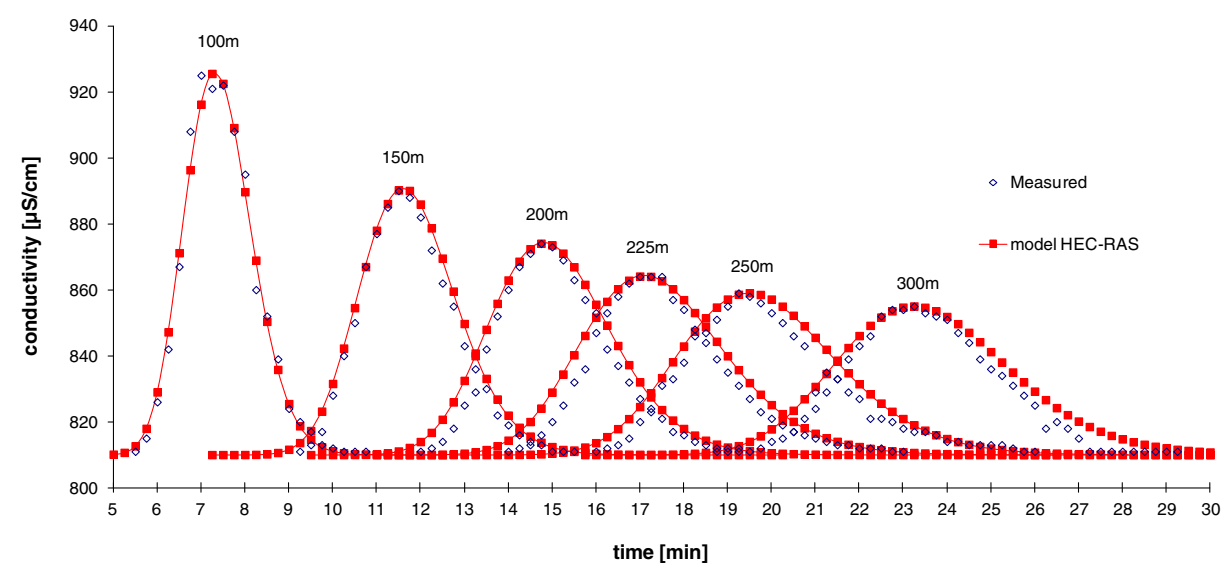

Fig. 5 Conductivity distribution during the measurement time - comparison of measured values and results of numerical model HEC-RAS 
The first way of the transverse dispersion coefficient determination again consists of simulation of tracer experiment (concentration distribution) for various values of the transverse dispersion coefficient. The basis for this simulation is the 2-D analytical solution of Eq. (1) for continuous tracer injection (Demetracopoulos and Stefan 1983):

$$
c(x, y)=\frac{q_{t} \cdot c_{t}}{h \sqrt{4 \pi D_{T} x u_{p}}} \exp \left(-\frac{y^{2} u_{p}}{4 x D_{T}}\right)
$$

where $q_{t}$ is a tracer injection discharge $\left(\mathrm{m}^{3} . \mathrm{s}^{-1}\right), c_{t}$ is a tracer injection concentration $\left(\mathrm{kg} . \mathrm{m}^{-3}\right)$, $u_{p}$ is the mean cross-sectional velocity $\left(\mathrm{m} \cdot \mathrm{s}^{-1}\right), D_{T}$ is the transverse dispersion coefficient $\left[\mathrm{m}^{2} \cdot \mathrm{s}^{-1}\right], x$ is the distance from the tracer source [m], and $h$ is the water depth [m].

A similar methodology as for the longitudinal dispersion coefficient was used. All values in Eq. (5) were known from our field measurements (i.e., the distance $x$, the time $t$, the mean cross-sectional velocity $u_{p}$, the tracer concentration $c_{t}$, the tracer discharge $q_{t}$, the depth $h$ ), except of the value of the transverse dispersion coefficient $D_{T}$. Similarly to the previous case, the best estimation of $D_{T}$ value arises from the best fit between measured and modelled values (provided by Eq. 5). For the determination of the best fit between measured and modelled values, the method of least squares was used. It means, that the sum of squared residuals (differences between measured and modelled values) for various values of $D_{T}$ was evaluated. The minimal value of the squared residuals sum determines the best estimation of the transverse dispersion coefficient value $D_{T}$. This procedure was also performed for all measured cross sections and each experiment (see Fig. 6).

For the determination of the transverse dispersion coefficient by using a numerical model, the model MODI was applied. This model was developed on the Institute of Hydrology SAS (Velísková 1995) for prediction of pollutant dispersion in natural streams. It is based on the ideas of Luk et al. (1990) and uses the so-called stream-tube concept. Based on this conception, the river channel is divided along its width into flow tubes of different widths, but with the same discharge. Each stream-tube is divided into elements of variable length. The length of each individual element is established so that the Courant number equals one. Automatic generation of element lengths by the program under this condition eliminates the frequent cause of numerical instability. Another condition of numerical stability is the condition for transverse deviation (Vreugdenhil 1989).

The MODI model can simulate the dispersion of pollutant under steady flow conditions in non-prismatic channels, self-purification effect and arbitrarily situated unsteady sources of pollution.

Experiment Nr.DT5R distance $30 \mathrm{~m}$

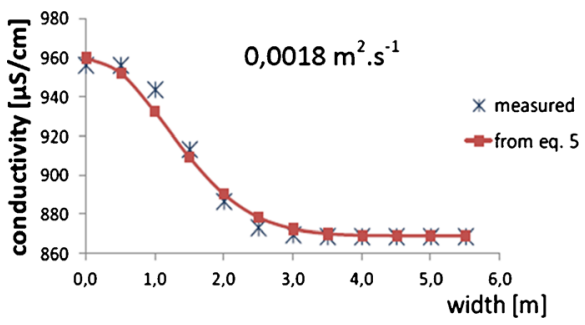

Experiment $\mathrm{Nr}$. DT5R distance $150 \mathrm{~m}$

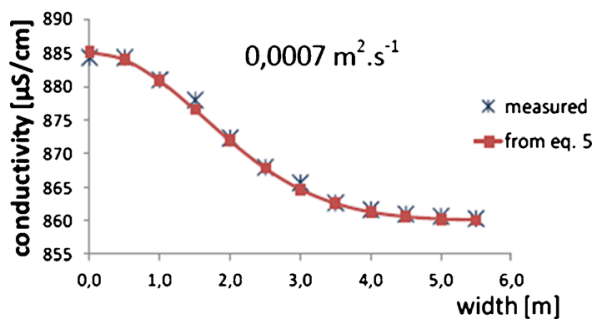

Fig. 6 Comparison of measured values from field experiments and results from analytical solution of advectiondispersion equation (Eq. 5) 
The model was used for tracer experiment simulations, similarly as in the case of longitudinal dispersion coefficient, but with various values of transverse dispersion coefficients. Results of simulations were compared with values obtained during field measurements and the minimal difference between measured and modelled values determines the value of the transverse dispersion coefficient for each one of the experiments. Partial results of one numerical experiment set could be seen in Fig. 7.

\section{Results and Discussion}

Data obtained from field experiments and measurements were processed by foregoing methods. Values of longitudinal dispersion coefficient are summarised in Table 1.

The range of mean values of this coefficient determined based on the analytical solution of advection-dispersion equation (Eq. 3) is $0.12-0.18 \mathrm{~m}^{2} . \mathrm{s}^{-1}$, and from the evaluation of statistical parameters is $0.13-0.22 \mathrm{~m}^{2} . \mathrm{s}^{-1}$. The dimensionless coefficient values were in the range (4.1 to 7.5$)$.

There is not much difference between the two range values. It is convenient to mention, that these ranges of values are closer to values obtained in laboratory flumes than in natural conditions (Fischer et al. 1979; Ríha et al. 2000). This is acceptable because this part of the stream was selected as a straight reach of a quasi-prismatic channel. On the other hand, in the case of longitudinal dispersion coefficient values determined from the application of the onedimensional simulation model HEC-RAS, the differences among these values and values from both previous methods (Eqs. 3 and 4) are distinct. Besides, the values of this coefficient obtained by the model are more variable along the investigated reach of the stream. The results indicate that the so-called mixing length (length along which the tracer spreads across the whole width of a stream) was not estimated correctly. For this reason, it is necessary to perform another set of experiments, where the tracer concentration distribution across and along the stream will be simultaneously checked.

The transverse dispersion coefficient values are summarised in Table 2. The values of this coefficient were measured during two different discharges in the stream $\left(0.15 \mathrm{~m}^{3} . \mathrm{s}^{-1}\right.$ and

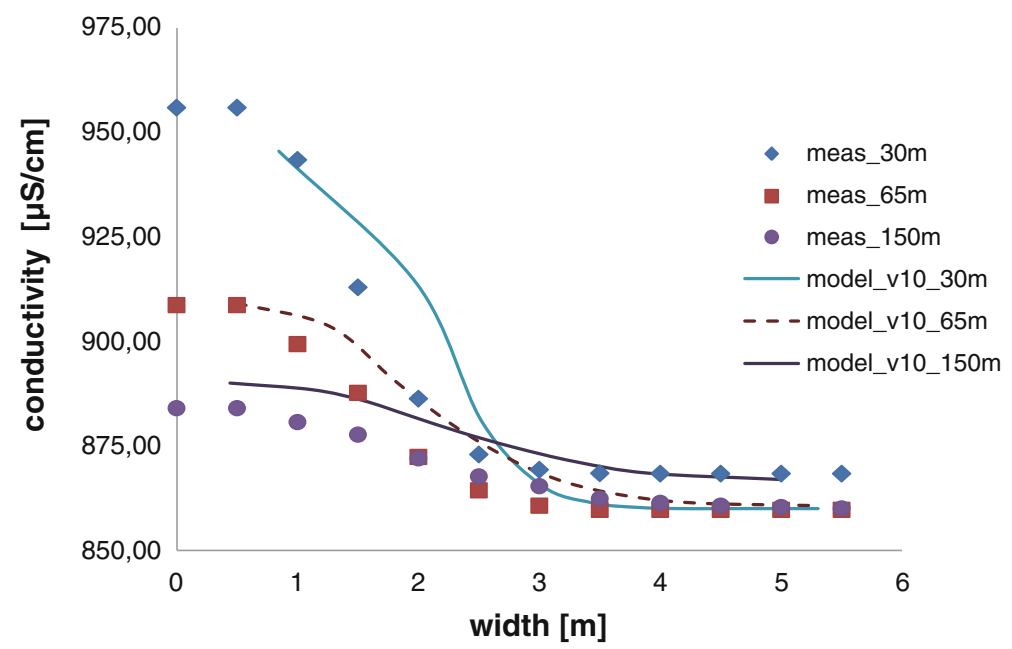

Fig. 7 Results of application of the model MODI - conductivity distribution along the stream width 
Table 1 Longitudinal dispersion coefficient values

\begin{tabular}{llll}
\hline $\begin{array}{l}\text { Distance of the cross section } \\
\text { from the tracer source }[\mathrm{m}]\end{array}$ & $\begin{array}{l}\text { Eq. (3) } \\
{\left[\mathrm{m}^{2} \cdot \mathrm{s}^{-1}\right]} \\
\text { Mean }\end{array}$ & $\begin{array}{l}\text { Eq. (4) } \\
{\left[\mathrm{m}^{2} . \mathrm{s}^{-1}\right]} \\
\text { Mean }\end{array}$ & $\begin{array}{l}\text { HEC-RAS } \\
{\left[\mathrm{m}^{2} . \mathrm{s}^{-1}\right]}\end{array}$ \\
\hline 97 & 0.12 & 0.13 & 0.093 \\
150 & 0.12 & 0.13 & 0.322 \\
200 & 0.14 & 0.15 & 0.451 \\
250 & 0.18 & 0.22 & 0.596 \\
300 & 0.17 & 0.21 & 0.283 \\
\hline
\end{tabular}

$0.5 \mathrm{~m}^{3} \cdot \mathrm{s}^{-1}$ ), and their values were determined for both flow conditions. The range of mean values of this coefficient, estimated based on the analytical solution of the advection-dispersion equation (Eq. 5), varied between 0.006 and $0.0019 \mathrm{~m}^{2} \cdot \mathrm{s}^{-1}$. The mean values of the transverse dispersion coefficient, coming from the application of the numerical model MODI, is in the range $0.001-0.0024 \mathrm{~m}^{2} . \mathrm{s}^{-1}$. All values are within the range of transverse dispersion coefficient values published in the literature (Fischer et al. 1979; Ríha et al. 2000; Boxall and Guymer 2001; Rathbun and Rostad 2004) and their fluctuations are similar.

The differences of the coefficient values in the individual cross sections along the stream are higher when using the analytical solution of Eq. (5). This can be caused by the model MODI, simulating flow conditions in the investigated part of the stream in more detail than the analytical solution (Eq. 5), because the input data to MODI model are distribution of depths and velocities along the width of the cross sections, but the analytical solution uses only mean values of these characteristics of flow.

Dimensionless values of the transverse dispersion coefficient estimated by Eq. (2) have smaller variability in the case of applying the MODI model $\left(\mathrm{p}_{0.15}=0.07-0.11 ; \mathrm{p}_{0.5}=0.15-0.17\right)$ than from Eq. (5) $\left(\mathrm{p}_{0.15}=0.06-0.16 ; \mathrm{p}_{0.5}=0.06-0.37\right)$. It is obvious that these dimensionless values slightly increase with rising discharge in both ways of determination. This is interesting because this form of dispersion coefficient should be partially independent to flow condition changes (it was calculated by Eq. 2, in which the water depth is used as a parameter; on the other hand, the application of this relation is used for determination of the coefficient values in different flow conditions).

Already during field measurements, it was observed that the investigated part of the Mala Nitra stream was not the prismatic channel originally assumed, and this was seen also from the numerical simulations results. Zones with relatively thick silt deposits or other objects influencing the velocity field existed there. As a result, the tracer spreading was not optimum and its retention in the so-called "dead zones" was causing the deformation of tracer cloud. For

Table 2 Transverse dispersion coefficient values

\begin{tabular}{|c|c|c|c|c|}
\hline $\begin{array}{l}\text { Distance of the cross section } \\
\text { from the tracer source }[\mathrm{m}]\end{array}$ & $\begin{array}{l}\text { Eq. }(5) \\
\left(\mathrm{Q}=0.15 \mathrm{~m}^{3} \cdot \mathrm{s}^{-1}\right) \\
\text { Mean value } \\
{\left[\mathrm{m}^{2} \cdot \mathrm{s}^{-1}\right]}\end{array}$ & $\begin{array}{l}\text { Eq. }(5) \\
\left(\mathrm{Q}=0.5 \mathrm{~m}^{3} \cdot \mathrm{s}^{-1}\right) \\
\text { Mean value } \\
{\left[\mathrm{m}^{2} \cdot \mathrm{s}^{-1}\right]}\end{array}$ & $\begin{array}{l}\text { MODI } \\
\left(\mathrm{Q}=0.15 \mathrm{~m}^{3} \cdot \mathrm{s}^{-1}\right) \\
\text { Mean value } \\
{\left[\mathrm{m}^{2} \cdot \mathrm{s}^{-1}\right]}\end{array}$ & $\begin{array}{l}\text { MODI } \\
\left(\mathrm{Q}=0.5 \mathrm{~m}^{3} \cdot \mathrm{s}^{-1}\right) \\
\text { Mean value } \\
{\left[\mathrm{m}^{2} \cdot \mathrm{s}^{-1}\right]}\end{array}$ \\
\hline 30 & 0.0032 & 0.0075 & 0.0019 & 0.0030 \\
\hline 97 & 0.0021 & 0.0019 & 0.0018 & 0.0030 \\
\hline 150 & 0.0011 & 0.0011 & 0.0014 & 0.0033 \\
\hline
\end{tabular}


these reasons, the field measurements should be repeated and extended, with the aim to verify, confirm or refute existing results and clarify obscurities.

\section{Conclusions}

The Water Framework Directive requires as a goal to achieve and maintain "good water quality" status. For surface waters, the main criterion is the ecological and chemical status. Nowadays, the mathematical and numerical modelling allows evaluating various situations of contaminant spreading in rivers (from everyday wastewater disposal through fatal accidents and discharges of the toxic substances) without immediate destructive impact to the environment. One of the most important inputs for the pollution spreading models in streams is the value of the dispersion coefficient.

The paper describes various ways for the determination of the longitudinal and transverse dispersion coefficient from field tracer experiments performed at a small adjusted stream. Basic hydrodynamic parameters during the experiments were: the discharge $Q=0.138$ $0.553 \mathrm{~m}^{3} . \mathrm{s}^{-1}$, the stream depth $h=0.29-0.48 \mathrm{~m}$ and the stream width $B=5.2-5.9 \mathrm{~m}$. The range of obtained longitudinal dispersion coefficient values, after considering the mixing length, is $0.14-0.6 \mathrm{~m}^{2} \cdot \mathrm{s}^{-1}$ and the dimensionless coefficient values were in the range 5 to 7.5 . The range of obtained transverse dispersion coefficient is $0.001-0.003 \mathrm{~m}^{2} . \mathrm{s}^{-1}$ for the discharge value of $0.15 \mathrm{~m}^{3} . \mathrm{s}^{-1}$, and $0.001-0.008 \mathrm{~m}^{2} \cdot \mathrm{s}^{-1}$ for the discharge value $0.5 \mathrm{~m}^{3} \cdot \mathrm{s}^{-1}$ It is convenient to mention, that their ranges are closer to values obtained in laboratory flume than in natural streams (Fischer et al. 1979; Ř́ha et al. 2000).

The results can be used for future numerical simulation of water quality in the investigated stream or a similar one, but it is necessary to notice that the obtained values - especially for the longitudinal dispersion coefficient — are valid for the "transitional" zone primarily, where the tracer is not spread across the entire width of the stream. And for this reason it is necessary to perform further experiments and analysis to verify and validate the results.

Acknowledgments This paper was prepared with the support of the Scientific Grant Agency APVV within the implementation of the project no. APVV-0274-10, and it is also the result of the project implementation ITMS 26240120014 Centre of excellence for protection and use of landscape and biodiversity supported by the Research \& Development Operational Programme funded by the ERDF. An initial version of this paper was presented at the 8th International Conference of the EWRA in Porto, Portugal, June 26-29, 2013.

\section{References}

Abbott MB (1978) Commercial and scientific aspects of mathematical modelling. Applied Numerical Modelling. Proc 2nd International Conference, Madrid, September 1978, 659-666

Bansal MK (1971) Dispersion in natural streams. J Hydraul Div 97(HY11):1867-1886

Boxall JB, Guymer I (2001) Estimating transverse mixing coefficients. Water Marit Eng 4:263-275, ISSN 1472 4561

Brown LC, Barnwell TO (1987) The enhanced stream water quality models QUAL2E and QUAL2E-UNCAS: documentation and user manual. Env. Res. Laboratory. US EPA, EPA /600/3-87/007, Athens, GA

Cunge JA, Holly FM, Verwey A (1985) Practical aspects of computational river hydraulics. Energoatomizdat, Moskva, in Russian

Demetracopoulos AC, Stefan HG (1983) Transverse mixing in wide and shallow river. Case study. J Environ Eng ASCE 109(3):685-699

DHI-http://mikebydhi.com/ 
Elder JW (1959) Dispersion of marked fluid in turbulent shear flow. J Fluid Mech 5(Part 4):544-560

Fischer HB, List EJ, Koh RCY, Imberger J, Brooks NH (1979) Mixing in inland and coastal waters. Academic, New York

Jirka GH, Doneker RL, Hinton SW (1996) User's Manual for CORMIX: A Hydrodynamic Mixing Zone Model and Decision Support System for Pollutant Discharges into Surface Waters, DeFrees Hydraulics Laboratory, Cornell University: Ithaca, NY

Jolánkai G (1992) Hydrological, chemical and biological processes of contaminant transformation and transport in river and lake systems. A state of the art report. UNESCO, Paris, $147 \mathrm{pp}$

Jolánkai G (2000) WQMCAL_-Description of the CAL programme on Water Quality Modelling, Version 2, Final report, Budapest, www.portal.unesco.org

Karcher MJ, Gerland S, Harms IH, Iosjpe M, Heldal HE, Kershaw PJ, Sickel M (2004) The dispersion of 99Tc in the Nordic Seas and the Arctic Ocean: a comparison of model results and observations. J Environ Radioact 74(1-3):185-198

Kosorin K (1995) Dispersion coefficient for natural cross sections of surface streams. J Hydrol Hydromech 43(1-2):93-101 (in Slovak)

Krenkel PA, Orlob G (1962) Turbulent diffusion and reaeration coefficient. J Sanit Eng Div ASCE 88(SA2):53-83

Limerinos JT (1970) Determination of the Manning coefficient for measured bed roughness in natural channels. Water Supply paper 1898-B, U.S. Geological Survey, Washington D.C.

Luk GKY, Lau YL, Watt WE (1990) Two-dimensional mixing in rivers with unsteady pollutant source. J Environ Eng ASCE 116(1):125-143. doi:10.1061/(ASCE)0733-9372(1990)116:1(125)

McInstyre N, Jackson B, Wade AJ, Butterfield D, Wheater HS (2005) Sensitivity analysis of a catchment-scale nitrogen model. J Hydrol 315(1-4):71-92

Parker FL (1961) Eddy diffusion in reservoirs and pipelines. J Hydraul Div 87(HY3):151-171

Pekárová P, Velísková Y (1998) Modelling of water quality in Ondava river catchment. VEDA, Bratislava (in Slovak)

Rankinen K, Lepisto A, Granlund K (2002) Hydrological application of the INCA model with varying spatial resolution and nitrogen dynamics in a northern river basin. Hydrol Earth Syst Sci 6(3):339-350

Rathbun RE, Rostad CE (2004) Lateral mixing in the Mississippi River below the confluence with the Ohio River. Water Resour Res 40(5):W052071-W0520712

Ř́ha J, Doležal P, Jandora J, Ošlejšková J, Ryl T (2000) Surface water quality and its mathematical modelling. NOEL, Brno (in Czech)

Rossman LA (2007) Storm water management model user's manual, EPA/600/R-05/040. U.S. Environmental Protection Agency, Cincinnati

Runkel RL (1998) One-dimensional transport with inflow and storage (OTIS): a solute transport model for streams and rivers. U.S. Geological Survey, Water-Resources Investigations Report 98-4018, Denver, Colorado

Sanders TG, Ward RC (1978) Relating stream standards to regulatory water quality monitoring practices. Proc. of the American Water Resources Association Symposium on Establishment of Water Quality Monitoring Programs, June 12-14

Socolofsky SA, Jirka GH (2005) Cven 489-501: Special Topics in Mixing and Transport Processes in the Environment. Engineering-Lectures. 5th Edition, Coastal and Ocean Engineering Division, Texas A\&M University, M.S. 3136, College Station, TX 77843-3136

Swamee PK, Pathak SK, Sohrab M (2000) Empirical relations for longitudinal dispersion in streams. J Environ Eng 126(11):1056-1062

USDA-http://go.usa.gov/KFO

Velísková Y (1995) Judgement of dispersion properties in surface water under 2D idealization. Doctoral Dissertation. Institute of Hydrology SAS, Bratislava, Slovakia. (in Slovak)

Vreugdenhil CB (1989) Computational hydraulics. Springer, Berlin

Yotsukura N, Sayre WW (1976) Transverse mixing in natural channels. Water Resour Res 12(4):695-704 